\title{
Influence of etch pit development on the surface area and
}

\section{dissolution kinetics of the orthoclase $(001)$ surface}

Marion Pollet-Villard $^{1 *}$, Damien Daval ${ }^{1,2}$, Bertrand Fritz ${ }^{1}$, Kevin G. Knauss ${ }^{2}$, Gerhard

Schäfer ${ }^{1}$ and Philippe Ackerer ${ }^{1}$

${ }^{1}$ Laboratoire d'Hydrologie et de Géochimie de Strasbourg, Université de Strasbourg/EOST,

CNRS, 67084, Strasbourg, France

${ }^{2}$ Earth Sciences Division, Lawrence Berkeley National Laboratory, Berkeley, CA 94720, USA

*Correspondence: Marion Pollet-Villard (polletvillard@ unistra.fr), +33 (0)368 850568 ,

Laboratoire d'Hydrologie et de Géochimie de Strasbourg, Université de Strasbourg/EOST,

CNRS, 67084, Strasbourg, France

Keywords: reactive surface area; dissolution kinetics; etch pits; orthoclase (001) face; hydrothermal alteration 


\section{ABSTRACT}

The (001) orthoclase surface was dissolved at $180^{\circ} \mathrm{C}$ and at far from equilibrium conditions with an alkaline solution $\left(\mathrm{pH}_{180^{\circ} \mathrm{C}}=9\right)$ in a titanium open flow reactor. Vertical scanning interferometer (VSI) and atomic force microscope (AFM) surface monitoring were periodically used during the reaction process in order to quantify the surface topography evolution. The dissolution of the (001) orthoclase face occurs with the formation of diamond shape etch pits. Diamond pit diagonals are parallel to the [100] and [010] axes, and the pit walls are parallel to $(656),(6 \overline{5} 6),(\overline{6} 511)$ and $(\overline{6} \overline{5} 11)$ planes. The etch pit size and global surface retreat of the (001) surface were found to increase linearly with time. Based on statistical treatments of etch pit development monitoring by AFM, we designed a numerical model aimed at reproducing and quantifying the total surface evolution. Numerical results show that the stabilization of etch pits doubles the calculated dissolution rate, partly due to the intrinsically higher reactivity of pit walls, consistent with a dissolution process in line with the periodic bond chain $(\mathrm{PBC})$ theory. In addition, normalizing the dissolution rate by the initial surface area of the (001) orthoclase surface induces a $20 \%$ overestimation of the calculated dissolution rate, while the total surface area of the dissolving face reaches a steady state after a few days of reaction. Additional simulations conducted to assess the impact of defect parameters revealed a weak dependence of the dissolution rate on dislocation density, consistent with previous experimental observations. Overall, the combined effect of the various defect parameters does not affect the dissolution rate by more than an order of magnitude, and probably contributes to a moderate extent to the dispersion of mineral dissolution rate data reported in the literature. 


\section{INTRODUCTION}

Predicting the evolution of mineral dissolution rates represents a critical issue for several geological, environmental and engineering concerns (e.g. Knauss et al., 2005; Fritz et al., 2010; Maher et al., 2014). In that respect, a substantial amount of laboratory and field studies dedicated to fluid/rock interactions have been conducted over the past decades in order to enlighten mineral dissolution mechanisms and to develop more relevant dissolution models (White and Brantley, 1995). A significant proportion of these studies have shown that mineral dissolution was often characterized by the formation of etch pits, which may represent a major driver of the dissolution process (e.g. Arvidson et al., 2003; Beig and Luttge 2006; Berner et al., 1980; Lasaga and Luttge, 2001; MacInnis and Brantley, 1992, 1993). As such, the description of pit nucleation and growth seems to be a key parameter to describe mineral dissolution kinetics and understand the dissolution mechanisms at a molecular level.

Among the obvious complicating factors resulting from etch pit formation is the increase of mineral specific surface area. Whereas most of the conventional studies dedicated to measuring the dissolution kinetics of silicates report rate data that are normalized to the initial surface area (e.g. Brantley et al. 2008), both direct measurements of surface topography using atomic force microscopy (AFM) and vertical scanning interferometry (VSI), as well indirect measurements of specific surface area using gas adsorption methods such as BET demonstrated that the surface area of dissolving minerals was changing over the course of the dissolution reaction (Arvidson et al., 2003; Gautier et al., 2001; Godinho et al., 2012; MacInnis and Brantley, 1992, 1993; Smith et al., 2013). For example, Arvidson et al. (2003) showed that calcite surface topography continuously evolved during several weeks of reaction, and some studies questioned the idea that surface morphology could eventually reach a steady-state (MacInnis and Brantley, 1992, 1993). With an empirical model of surface evolution, Lüttge (2005) showed that the use of geometric surface area (defined as the surface 
area calculated from the crystal dimensions and ignoring surface roughness) overestimates the actual dissolution rate of minerals, emphasizing that the increase of the total surface area (defined as the surface area that takes into account the surface roughness) can significantly affect the overall dissolution rate.

In addition, an accurate description of the quantitative evolution of mineral surface area throughout the dissolution process may not be sufficient to provide satisfactory estimates of the actual mineral dissolution rates. In fact, several studies showed that even if the surface area is correctly modeled as a function of the reaction progress, the non-uniformly distributed reactivity of the surface could play an equally important role. For example, Gautier et al. (2001) observed that quartz dissolution rate reached a steady-state value in spite of the continuous increase of the BET surface area throughout the reaction progress. They concluded that etch pit walls are unreactive and contribute negligibly to the mineral dissolution, such that normalizing the rate data to the initial geometric surface area would provide a better estimate of quartz dissolution rate. Similarly, Godinho et al. (2012) and Smith et al. (2013) reported that the progressive stabilization of poorly reactive crystallographic planes may eventually control the long-term dissolution rate of fluorite and calcite, respectively. Finally, Scislewski and Zuddas (2010) showed that surface evolution and mineral reactivity are highly correlated, so that their impacts on dissolution rate are virtually impossible to distinguish. More generally, the complexity of monitoring experimentally the evolution of the surface area as a function of the reaction progress has long prevented its characterization, promoting the alternate development of theoretical approaches (Kurganskaya and Luttge, 2013; Lasaga and Blum, 1986; Lasaga and Luttge, 2001; Luttge, 2005; Meakin and Rosso, 2008; Nicoleau et al., 2015).

In this study, we provide new data on etch pit morphology, nucleation, growth, and contribution to the dissolution rate of orthoclase mineral, which was selected because of its 
prevalent occurrence in the Earth crust. Time-resolved dissolution experiments were carried out on the (001) orthoclase cleavage surface at $180^{\circ} \mathrm{C}$ in an alkaline solution at far-fromequilibrium conditions, and both VSI and AFM were used to provide a detailed crystallographic description of etch pit development. The topographic data were subsequently analyzed with variograms: this statistical tool consists in calculating the variance of the elevation difference $(\Delta z)$ as a function of the distance between two locations at the mineral surface exposed to the solution. The variogram shape provides information on the specific distribution of pits and their global size. The experimental data were subsequently used to develop a heuristic model aimed at reproducing numerically the surface topography evolution of the (001) orthoclase face. Because two datasets with similar variograms are statistically equivalent, the comparison between variograms resulting from the modeled and measured datasets was used to estimate the agreement between the experimental surface evolution and that reproduced by the model. This strategy enabled identifying the parameters which chiefly control the surface topography evolution, and made possible the development of sensitivity tests, which brought insights on the long-term reactivity of mineral surfaces.

\section{MATERIALS AND METHODS}

\subsection{Sample characterization and preparation}

The starting material is a natural orthoclase crystal coming from Afghanistan and identified by Rietveld refinement of X-ray diffraction patterns acquired on the powdered Kfeldspar. No minor phases were detected with X-ray diffraction or scanning electron microscopy (SEM). The chemical composition of the sample $\left(\mathrm{K}_{0.75} \mathrm{Na}_{0.22} \mathrm{Fe}_{0.01} \mathrm{Al}_{0.98} \mathrm{Si}_{3.02} \mathrm{O}_{8}\right)$ was determined by Inductively Coupled Plasma Atomic Emission Spectroscopy (ICP-AES; THERMO $^{\circledR}$ ICAP 6000 Series) after a standard lithium metaborate fusion at LHyGeS, 
Strasbourg, France (Table 1). The dissolution experiments were carried out on a (001) surface that was polished through a multi-step abrasive sequence using diamond suspensions of decreasing grain sizes and soft polishing cloths, with an ultimate polishing step in a colloidal silica suspension. The (001) face is a major cleavage plane whose reactivity is well documented in literature (e.g. Fenter et al., 2003, 2014; Teng et al., 2001). Sample surface was oriented using an electron backscatter diffraction (EBSD) detector attached to the SEM $\left(\right.$ TESCAN ${ }^{\circledR}$ Vega 2). The initial surface roughness was measured at different scales with AFM (Digital Instruments MultiMode AFM) and VSI (ZYGO ${ }^{\circledR}$ NewView 7300). The initial average arithmetic roughness $(R a)$, defined as the arithmetic average of the absolute values of the roughness profile (equation (1)) was $20 \mathrm{~nm}$ on $100 \mathrm{x} 100 \mu \mathrm{m}^{2}$ VSI images:

$R_{a}=\sqrt{\frac{1}{n} \sum_{i=1}^{n}\left(z_{i}-\bar{z}\right)^{2}}$

In equation (1), $i$ corresponds the index referring to each of the $n$ data points of the considered array, $z_{i}$, to its height and $\bar{z}$ to the mean height calculated over the considered array. The $R_{a}$ parameter as calculated above accounts for both low and high spatial frequencies, although the polishing procedure typically removed the high spatial frequencies more effectively.

\subsection{Aqueous alteration experiment}

The selected sample was mounted in a titanium support as designed by Daval et al. (2013) (Fig. 1a), where a Viton® disk held with a screw creates a non-wetted reference area. Partially masked samples were reacted in a synthetic alkaline solution in a Parr® mixed-flow reactor (Fig. 1b) at $180^{\circ} \mathrm{C}$ and 50 bars for up to 4.8 days.

Inlet solutions were prepared with ultrapure deionized water $(18.2 \mathrm{M} \Omega . \mathrm{cm})$ and analytical grade $\mathrm{NaOH}$ and $\mathrm{AlCl}_{3}$. The $\mathrm{pH}$ was adjusted with the concentration of $\mathrm{NaOH}$ in 
the solution $\left(\mathrm{pH}_{\mathrm{in}}\right.$ situ- $\left.180^{\circ} \mathrm{C}=9.0 \pm 0.1\right)$. No $\mathrm{pH}$ buffer was used in solution because, as it has been generally observed, buffers can influence the dissolution rate of silicates (Daval et al., 2010; Golubev and Pokrovsky, 2006). Investigating the dissolution of K-feldspar in alkaline solutions ensures that the dissolution process is not influenced by the formation of amorphous silica-rich surface layers (Hellmann, 1997) which could ultimately control the dissolution rate of the silicate mineral (Daval et al., 2013). To get rid of any potential inhibitory effect that $\mathrm{Al}$ may play on the dissolution rate (Gautier et al., 1994), the background concentration of Al was set a somewhat arbitrary value $([\mathrm{Al}]=3.8 \pm 0.2 \mathrm{ppm})$ high enough to consider that $\mathrm{Al}$ concentration was constant throughout the duration of the experiments.

During experiments, the outlet fluid was sampled every day. Compositions of the inlet and the outlet solutions were measured by ICP-AES (THERMO ${ }^{\circledR}$ ICAP 6000 Series). Aqueous concentrations at steady-state conditions are listed in Table 2. CHESS $^{\circledR}$ code $($ Van der Lee and De Windt, 2002) was used to determine the in situ $\mathrm{pH}$ and saturation indices with respect to orthoclase and secondary phases. All solutions were undersaturated with respect to any secondary phase.

\subsection{Global surface retreat measurements with VSI}

After dissolution experiments, the sample surface was analyzed with VSI in stitching mode (magnification: $5 \times$ ) to estimate the average change in height between the unweathered area and the reacted mineral surface (see Daval et al., 2013; Pollet-Villard et al., 2016 for further details). The experiment was stopped after $0.75,1.56,2.21$ and 4.80 days to measure the surface retreat as a function of time. The dissolution rate of the (001) face was calculated as follows:

$$
\mathrm{R}^{(001)}=\frac{\Delta \mathrm{h}^{(001)}}{\Delta \mathrm{t}} \overline{\mathrm{V}}^{-1}
$$


where $R^{(001)}\left(\mathrm{mol} . \mathrm{m}^{-2} . \mathrm{s}^{-1}\right)$ stands for the dissolution rate of the $(001)$ face, $\Delta h^{(001)}(\mathrm{m})$ is the surface retreat, $\Delta t(\mathrm{~s})$ is the alteration duration and $\bar{V}\left(\mathrm{~m}^{3} \cdot \mathrm{mol}^{-1}\right)$ is the molar volume of orthoclase.

\subsection{AFM monitoring of pit shape and distribution}

Because of the better lateral resolution of AFM compared to VSI, the sample surface was also monitored by AFM at a higher magnification in order to determine the geometry and the abundance of etch pits as a function of time. Etch pit dimensions and angles of the pit walls relative to the (001) surface were calculated on raw data with the VISION ${ }^{\circledR}$ software by monitoring approximatively fifty etch pits for each time step. Any possible artifact due to the probe geometry has been checked while measuring pit wall angles. The $10^{\circ}$ cantilever tilt angle and the apex angles of the tip $\left(15^{\circ}\right.$ and $25^{\circ}$ on the side of the tip and $17.5^{\circ}$ on the front $)$ do not interfere with the measurements as long as the angle between pit walls and the (001) surface is lower than $55^{\circ}$, which has been verified for all measurements. In addition, systematic comparisons between the VSI and AFM data collected on similar locations of the sample surface ensured that the AFM data were negligibly affected by possible distortions due to the AFM scanner.

The cell parameters of orthoclase as determined by Colville and Ribbe, (1968) were used to calculate the theoretical angles between the planes which were considered.

\subsection{Numerical modelling}

To quantify the evolution of the surface area of the (001) face over the course of the dissolution reaction, an empirical model aimed at reproducing the nucleation and growth of etch pits as a function of time was designed. This model also accounts for the overall surface retreat measured by VSI. 
The model is based on the description of a crystal by $N_{x} \times N_{y} \times N_{z}$ elementary cells (ECs) where $N_{x}$ (respectively $N_{y}$ and $N_{z}$ ) represents the number of ECs following $x$ (respectively $y$ and $z$ ) directions. The ECs have a hexahedral shape, and the cell dimensions along $x, y$ and $z$ directions are respectively $0.2 \mu \mathrm{m}, 0.2 \mu \mathrm{m}$ and $0.05 \mu \mathrm{m}$ (Table 3). The size of the ECs in the lateral $x$ and $y$ directions is similar to the pixel dimensions at the AFM field of view that we used $\left(100 \times 100 \mu \mathrm{m}^{2}\right)$. For each EC, the model lists the orientation of the faces which contact the fluid. For each dissolution direction $i(i=x, y$ or $z)$, a constant "period" $k_{i}$ is defined (see Table 3 and section 3.3). This parameter corresponds to the time required to dissolve the EC which contacts the fluid in the $i^{\text {th }}$ direction. If more than one face is in contact with the fluid, the time required to dissolve the corresponding $\mathrm{EC}$ is set equal to that of the fastest dissolving face which contacts the solution (i.e. the smallest $k_{i}$ value).

To initiate etch pit openings, specific lines of ECs that we refer to as 'defects' are randomly uniformly distributed in the volume of the modeled crystal structure. These ECs dissolve at a specific shorter period labelled $k_{d}$. The amount of defects outcropping at the surface of the (001) face was supposed to correspond to the etch pits density $\left(d_{s}\right)$ measured by AFM after the first time lap (see section 3.3), as commonly assumed for crystal dissolution characterization (e.g. Amelinckx, 1964; Brantley et al., 1986). From a crystallographic standpoint, these lines of ECs may simulate screw dislocation lines, at which deep etch pits usually nucleate and grow (e.g. Duckworth and Martin, 2004; Gratz et al., 1991; MacInnis and Brantley, 1992). Because dislocations following the [001] direction are very common for naturally and experimentally deformed feldspars (Willaime and Gandais, 1977), the defect lines were oriented following the $z$ direction only. The length of the lines of ECs $\left(l_{d}\right)$, which can be converted into the number of ECs defects in the $z$ direction, is randomly set to a value which is assumed to follow a uniform distribution over an interval determined by the etch pit depth observed experimentally. Because in the real world, dislocations cannot start or stop 
inside a crystal, it may seem improper to define a finite length for the dislocation line that would be smaller than the crystal size. However, dislocations are rarely straight lines running through the crystal volume; most often, the dislocation structure is complex, with several changes in the line direction. As such, $l_{d}$ may be understood as the length of the portion of any dislocation line that is parallel to the $z$ direction. Finally, the nucleation of new pits resulting from the global surface retreat, which is responsible for the gradual outcrop of additional deeper defect lines, is also taken into account. Because the etch pit density was not homogeneously distributed in the crystal volume (see section 3.3), a supplementary parameter $\left(d_{v}\right)$ corresponding to the density of dislocation lines parallel to the [001] direction which were not originally outcropping at the orthoclase surface was defined according to the timeresolved AFM measurements. These corresponding defects were randomly positioned in the inner volume of the modeled crystal structure following a uniform distribution.

At each time step, the model counts the number of existing ECs, the number of faces in contact with the fluid and the face orientation. These data are subsequently used to compute the dissolved volume, the mineral surface area and, in turn, the dissolution rate per unit of area and per iteration.

All of the above-described parameters (i.e. $k_{i}, k_{d}, d_{s}, d_{v}, l_{d}$ ) were fitted so that the model satisfactorily reproduces the observed surface evolution. The refinement of the various parameters was realized by comparing, for each time step, the calculated variograms based on the actual and modeled surfaces. A variogram $\gamma\left(\mathrm{m}^{2}\right)$ is a function which quantifies the degree of spatial dependence. It is defined as the variance of the difference between the elevation values $(z$ in $\mathrm{m})$ at two locations $(i$ and $j)$ :

$$
\gamma_{i j}=\frac{1}{2} \operatorname{var}\left(z_{i}-z_{j}\right)
$$


In this study, variograms (more specifically, "semi-variograms", in accordance with the term $1 / 2$ presents in equations) were calculated with equation (4), where $N(d)$ denotes the set of pairs of observations $(i, j)$ such that the distance between the points $i$ and $j$ is equal to $d$ (Cressie, 1993). The distance $d(\mathrm{~m})$ was implemented using $\pm 0.1 \mu \mathrm{m}$ intervals.

$\gamma(d)=\frac{1}{2 N(d)} \sum_{\substack{i, j \\ d_{i j}=d}}\left|z_{j}-z_{i}\right|^{2}$

A good agreement between the variograms calculated on the observed and modeled surfaces ensures that the modeled surface is statistically equivalent to the actual surface. The appropriateness of the model was guaranteed by its ability to generate surface states on longer time durations (e.g. 4.8 days), which was assessed by comparing the variograms calculated on the modeled surface to those calculated on the actual surface.

\section{RESLUTS AND DISSCUSSION}

\subsection{Etch pit morphology evolution}

Etch pits that form on the (001) orthoclase face have a characteristic symmetric diamond shape (Fig. 2). Diamond diagonals belong to the (001) face and were found to be parallel to the [100] and [010] axes. Most etch pits have a flat bottom parallel to the (001) face. The angles between two consecutive edges of the pits were found to be constant through time $\left(63 \pm 5^{\circ}\right.$ and $121 \pm 5^{\circ}$, respectively; see Fig. 3 a). In contrast, the angle between the (001) plane and the etch pits walls, which was measured perpendicularly to the diamond ledges, decreased before reaching a constant value $\left(27 \pm 5^{\circ}\right)$ after two days of reaction (Fig. 3 b). Consistent with the angle measurements, most etch pits were observed to deepen linearly with time in the first two days of reaction prior to reaching a constant depth varying between 0.1 
and $2 \mu \mathrm{m}$, depending on the pits which were considered (Fig. $3 \mathrm{c}$ ). Note that this observation is consistent with the above-described model that we proposed to simulate etch pit opening mechanism, with the rapid and linear increase of their depth (see further discussion in section $3.3)$.

The maximal lateral extensions ( $L$ and $l$ ) of the etch pits corresponding to the diagonals of their diamond-shapes are represented in Fig. 4 (black points in Fig. 4c and 4d). Consistent with the conservation of the constant value of the $\alpha$ angle described previously, the etch pit size was found to increase linearly during dissolution process.

Finally, these observations indicate that etch pits reach a steady-state morphology after a few days of alteration. Therefore, the etch pit formation gave rise to four new $(\mathrm{hkl})$ planes that were exposed to the solution. Geometrical reconstruction of pits based on the measured angles between those planes revealed that they could be indexed as follows: $(656),(6 \overline{5} 6)$, $(\overline{6} 511)$ and $(\overline{6} \overline{5} 11)$. These calculated planes accurately reproduce the pit geometry with the smallest Miller indices that one could determine. Taken together, these planes define a diamond shape with $\alpha=123^{\circ}, \beta=58^{\circ}$ and $\gamma=32^{\circ}$ for $(656)$ and $(6 \overline{5} 6)$ planes and $30^{\circ}$ for $(\overline{6} 5$ 11) and ( $\overline{6} \overline{5} 11)$.

The crystallographic orientations that we determined above may provide a preliminary indication of their expected reactivity, as well as the consequence of their stabilization on the dissolution rate of the (001) surface. Recently, Pollet-Villard et al. (2016) showed that orthoclase dissolution rate complies with the periodic bond chain (PBC) theory (Hartman and Perdok, 1955). The PBC theory states that crystal faces can be sorted according to the number of uninterrupted chains of energetically strong bonds (PBC) they contain. Faces containing respectively $\geq 2,1$ and no $\mathrm{PBC}$ are commonly termed F- (for flat), S- (for stepped) and K- (for kinked) faces. Of note, the (001) surface belongs to the $\mathrm{F}_{1}$-category (Woensdregt, 1982), 
which has the lowest reactivity of the crystal structure. In contrast, the orientation of the etch pit walls which is reported above does not belong to the $\mathrm{F}_{1}$-category. Actually, the pit walls lie close to the $\{\overline{1} 12\}$ and $\{111\}$ families of planes, which were respectively classified as $F_{2}-$ and K-categories by Woensdregt (1982). If the reactivity of the pit walls complies with the PBC theory, they should therefore dissolve faster than the (001) face. Attempts to provide quantitative estimates of the pit wall reactivity are further discussed in section 3.4.

\subsection{Surface retreat measurements}

The surface retreat measurements carried out during the dissolution of the (001) orthoclase face are reported in Fig. 4b. The global retreat of the (001) surface increases linearly with time. This result validates the use of equation (2) to estimate the (001) dissolution rate, which was determined to be $(2.0 \pm 0.2) \times 10^{-8} \mathrm{~mol} \cdot \mathrm{m}^{-2} \cdot \mathrm{s}^{-1}$. Of note, this value is in close agreement with the far-from-equilibrium dissolution rate plateau of the (001) cleavage surface reported by Pollet-Villard et al., $2016\left(2.6 \times 10^{-8} \mathrm{~mol} \cdot \mathrm{m}^{-2} \cdot \mathrm{s}^{-1}\right)$. This value was averaged on rate data obtained for Gibbs free energy of K-feldspar dissolution ranging from 48 to $-89 \mathrm{~kJ} \cdot \mathrm{mol}^{-1}$, using the same experimental and analytical protocols.

\subsection{Parametrization and validation of the numerical model}

The time-resolved measurements of the surface retreat $(\Delta h)$, pit length $(L)$ and pit width $(l)$ were used to constrain the values of $k_{i}$ and $k_{d}$ (cf. Table 3 ). In addition, the range of steady-state etch pit depths, which corresponds to the depth at which the dislocation lines were exhausted in the $\mathrm{z}$ direction, was used to define the interval of ECs lengths $\left(l_{d}\right)$, here comprised between 0.05 and $2 \mu \mathrm{m}$. Finally, the surface density of etch pits determined after 
the first time lap was used to set $d_{s}$ equal to $2 \times 10^{5}$ ECs defects. $\mathrm{cm}^{-2}$. This value was greater than that used to define the density of dislocation lines parallel to the $z$ direction which were not originally outcropping at the crystal surface $\left(d_{v}=3 \times 10^{4} \mathrm{ECs} . \mathrm{cm}^{-2}\right)$, possibly because the mechanical polishing of the (001) surface gave rise to an increase of the near surface damages such as dislocations (e.g. Lucca et al., 2006). Overall, the defect densities implemented in our numerical simulations are on the same order of magnitude as the dislocation or pit densities measured in other studies. For example, Marshall and McLaren (1977) and Olsen and Kohlstedt (1984) have reported that the dislocation density was below $10^{4} \mathrm{~cm}^{-2}$ and between $4 \times 10^{7}$ and $7 \times 10^{8} \mathrm{~cm}^{-2}$ for naturally and deformed plagioclase feldspars, respectively. Yund et al. (1981) measured dislocation densities below $10^{6} \mathrm{~cm}^{-2}$ and equal to $5 \times 10^{9} \mathrm{~cm}^{-2}$ for natural and experimentally deformed albite, respectively. Of note, higher dislocation densities (up to $10^{9}-10^{12} \mathrm{~cm}^{-2}$ ) may be measured for minerals which experienced important mechanical stress (Blum et al. 1990; Casey et al., 1988a; Holdren et al. 1988; Yund et al., 1981). As long as one supposes that the dislocation density reported in the present study is correctly approximated by the measured etch pit density, these observations suggest that the dislocation density of the orthoclase sample used in the present study falls in the lower range of dislocation densities reported for tectosilicates, possibly indicating that our sample did not experience high levels of stress or deformation.

The evolution of the actual and modeled (001) orthoclase surfaces is shown in Fig. 5. On a qualitative standpoint, the modeled surface evolution is similar to the measured surface evolution, with the linear increase of pit dimensions in the $x$ and $y$ directions over time. The coalescence of etch pits is rapidly observed, similarly to other studies which described etch pit growth driven by dislocations on carbonate minerals (e.g. Duckworth and Martin, 2004; MacInnis and Brantley, 1992). 
The validity of our model and its parametrization was further assessed by calculating the surface's topography variograms (Fig. 6). Consistent with the visual AFM observations, the variograms calculated on the measured (black squares) and simulated (grey squares) surface topographies verified that etch pit growth is a linear function of time, as denoted by the increase of the correlation length (indicated by the dashed line), which represents the average pit size. The global roughening of the surface is also evidenced by the increase of the variance of the surface elevation (corresponding to the level of the plateau in Fig. 6) during the dissolution process due to the opening and deepening of etch pits.

Of note, the variograms calculated on the modeled and measured surface topographies do not overlap for $t_{1}=0.75$ day. This mismatch was attributed to the starting roughness of the sample, which was not negligible compared to the surface topography created by pit nucleation after short time durations (Fig. 7). Although the polishing efficiently removed the high frequency roughness, low frequency roughness (i.e. rounding) persisted, such that the initial surface topography was non-negligible when the pit depth was limited, and resulted in an increase of the variance in the calculated variogram. To overcome this complicating factor, an empirical deformation of the starting surface was introduced in the model, which we found to be correctly accounted for by the following equation:

$z^{\prime}=z+0.058 \exp \left(-\frac{(x-50)^{2}}{144}\right)$

Applying this equation to the entire surface results in a convex correction with a maximal $z$ heightening of $0.058 \mu \mathrm{m}$. This heightening corresponds to the experimental value of the maximal height difference observed in the starting surface topography (Fig. 7). Strikingly, when this correction is taken into account for the first simulation, the variogram calculated on the modeled rounded surface topography at $t=t_{1}$ (dark grey curve) is equivalent to the 
variogram calculated on the measured surface topography. When $t>t_{1}$ the effect of the initial topography becomes negligible compared to the roughness resulting from etch pit formation.

In addition, the variance of the surface topography calculated on the modeled surface at $t_{2}=1.56$ days (Fig. 6 b) slightly overestimates the variance calculated on the surface monitored experimentally. Possible explanations which could account for such a gap include a slight overestimation of the actual defect density within the dissolved volume between $t_{l}$ and $t_{2}$ (which would locally be comprised between $d_{s}$ and $d_{v}$ ), although this overestimation has an overall negligible impact on the general agreement between the evolution of the measured and calculated variances (see insert in Fig. 6d, where the reported variances were estimated from the $\gamma$ plateau values observed in graphs 6a-d).

Finally, the output of the numerical model was used to calculate the mean dissolution rate of orthoclase following the expression:

$$
R_{g}(t)=\frac{1}{S\left(t_{0}\right)} \frac{\Delta n}{\Delta t} \quad \text { with } \quad \Delta n=V_{d i s s} \bar{V}^{-1}
$$

where $R_{g}$ stands for the dissolution rate $\left(m o l \cdot m^{-2} \cdot s^{-1}\right), S\left(t_{0}\right)$ is the initial surface sample $\left(m^{2}\right)$, $\Delta n$ is the dissolved amount of orthoclase $(m o l), V_{\text {diss }}$ corresponds to the dissolved volume $\left(m^{3}\right)$ and $\bar{V}$ is the molar volume of orthoclase (in $m^{3} \cdot \mathrm{mol}^{-1}$ ). The calculated numerical dissolution rate after five days of alteration is $R_{g}=2.1 \times 10^{-8} \mathrm{~mol} \cdot \mathrm{m}^{-2} \cdot \mathrm{s}^{-1}$. In addition, the outputs of the simulations allow for the calculation of an average modeled surface retreat $\left(\Delta h_{m o d}\right)$, and an associated dissolution rate of $2.1 \times 10^{-8} \mathrm{~mol} \cdot \mathrm{m}^{-2} \cdot \mathrm{s}^{-1}$ (Equation (2)). These two values of the dissolution rate based on the numerical simulations are in perfect agreement with the experimental dissolution rate measured with VSI data $\left(R^{(001)}=(2.0 \pm 0.2) \times 10^{-8} \mathrm{~mol} . \mathrm{m}^{-}\right.$ $\left.{ }^{2} \cdot \mathrm{s}^{-1}\right)$, which is an additional verification of the model compliance. 
To sum up, variograms calculated on the modelled surface topography are equivalent to the variograms calculated on the measured surface topography. The ability of the model to accurately predict the statistical evolution of the surface area at $t=1.6,2.2$. and 4.8 days based on the tuning of the model parameters on the image acquired at $t=0.8$ day validates the formalism that was used to reproduce the evolution of the (001) orthoclase face during its dissolution. Therefore, one can confidently use this model (i) to anticipate the intrinsic longterm evolution of orthoclase dissolution rate, (ii) to estimate the contribution of etch pits to the overall dissolution rate, and (iii) to perform sensitivity tests and determine the parameters which primarily control K-feldspar reactivity.

\subsection{Numerical results}

\subsubsection{Long-term (001) cleavage surface reactivity and influence of etch pits}

As mentioned above, whether or not the surface topography of a dissolving mineral eventually reaches a steady-state configuration has been a debated question for over 20 years (e.g. Bandstra and Brantley, 2008; Godinho et al., 2012, 2014; Lüttge, 2005; MacInnis and Brantley, 1992, 1993; Smith et al., 2013). To bring new constraints on this question, the simulations described in the previous section were run until complete dissolution of the considered volume (Fig. 8).

Starting with an initial volume of limited dimensions $\left(V_{1}=100 \times 100 \times 4 \mathrm{~m}^{3}\right)$, our results show that the total surface area never reaches a steady-state until completion of the reaction (Fig. 8a), although its increase remains modest ( $20 \%$ reached after a reaction progress $(\xi)$ of $60 \%$, corresponding to ten days of reaction). This evolution of the surface area impacts the calculated dissolution rate as well. If normalized to the starting surface area $\left(S\left(t_{0}\right)\right)$, the progressive development of etch pits almost doubles the calculated dissolution rate (Fig. 8b). In contrast, if normalized to the ongoing surface area $(S(t))$ as occasionally 
performed in some studies (see Brantley and Chen, 1995 for details), the dissolution rate increases by $\sim 40 \%$ during the early stage of the process (for $0 \% \leq \xi \leq 20 \%$ ), prior to fluctuating around a constant value throughout the reaction progress. The attainment of a steady-state most likely reflects etch pit coalescence, and is in qualitative agreement with the results reported by e.g. Lasaga and Lüttge (2001). Note that the intrinsic increase of the dissolution rate in spite of the normalization to the current surface area is particularly interesting because it directly reflects the intrinsic contribution of pit wall reactivity to the overall dissolution rate of the (001) face (see further discussion below).

Starting with an initial volume with greater dimensions which approach the typical grain size that one could find in the field $\left(V_{2}=200 \times 200 \times 20 \mu \mathrm{m}^{3}\right)$ does not fundamentally change the conclusions which were drawn with the smaller volume (Figs. 8c, d). The only noticeable difference is that the surface area does eventually reach a steady state for $\xi \geq 10 \%$. Of note, the steady-state and/or maximal dissolution rates do not depend on the dimensions of the volume which is considered (compare Fig. 8b with Fig. 8d).

A final comment can be made regarding the contribution of etch pit walls to the overall dissolution rate of the (001) face. Arguably, if the dissolution rate of pit walls were identical to the reactivity of the (001) face, then normalizing the dissolution rate to the current surface $S(t)$ should result in a constant dissolution rate throughout the reaction progress. Instead, a 40\%-increase is observed. To determine the dissolution rate of the pit walls, an additional simulation was run on volume $V_{1}$, in which the dissolution of ECs which contact the solution with one (001) face only was suddenly set to 0 when the simulated surface reached a steady-state configuration. As such, only the pit walls kept driving the reaction, which allows for the calculation of their dissolution rate. The outputs of this simulation show that the pit walls dissolve $\sim 1$ order of magnitude faster than the (001) face (Fig. 9). As a consequence, this result is in qualitative agreement with the expected trend anticipated 
through the use of the PBC theory (see section 3.1), which sheds light on a possible global mechanism for mineral dissolution: the long-term dissolution rate of F-faces may systematically increase as a consequence of etch pit opening, because the pit wall orientations must belong to the S- or K-categories, whereas the long-term dissolution rate of K-faces may systematically decrease as a consequence of the stabilization of pit walls belonging to the $S$ or F-categories. This latter conjecture has been validated by e.g. Smith et al. (2013) for calcite. Therefore, it is probably safer to consider that the suggestion made by previous authors (e.g. Gautier al., 2001) that etch pit walls are unreactive should be restricted to the case of K- or S-faces only.

To conclude, etch pit nucleation is responsible for a maximum increase of $20 \%$ of the surface area of the $(001)$ face at $180{ }^{\circ} \mathrm{C}$ and $\mathrm{pH} 9$. When a steady-state dissolution regime is reached, normalizing the dissolution rate with respect to the initial vs. current surface area results in a difference of $\sim 25 \%$, which remains relatively modest. This result is likely related to the specific morphology of etch pits formed on this face: as a matter of fact, the majority of etch pits have a flat bottom which is also parallel to the (001) plane. As a consequence, the surface area of pit walls remains low compared to the total surface area, so that the contribution of their specific reactivity remains limited. However, such a conclusion should be restricted to the specific case of the studied surface, with its intrinsic physicochemical properties. To gain further insights on the parameters which control the dynamics of the mineral topography and surface reactivity, supplementary simulations were carried out by varying the numerical values of the parameters which describe the dissolution reaction.

\subsubsection{Influence of etch pit density and other defects parameters}

The final set of simulations was carried out on the biggest volume $\left(V_{2}\right)$ to make sure that possible steady-state behavior of the process would not be hindered by the early 
disappearance of the simulated volume. The supplementary simulations cover two orders of magnitude in terms of defect densities and maximal length of defects lines parallel to the $z$ axis. As for the specific defect dissolution rate value, the parameter $k_{d}$ was varied by a factor six, corresponding to the maximum variation that one could apply: actually, the variation range of this parameter is constrained by the model parameterization: since defects dissolve faster than regular ECs, their dissolution period must be smaller, so that the possible range of values for $k_{d}$ is quite restricted (see Table 3 ).

Increasing the defect density by up to two orders of magnitude results in the following two main consequences (see Figs. 10a-c and Fig 11a): (i) The attainment of a steady-state surface area occurs at a much smaller reaction progress (10\% vs. $60 \%$ for the simulation run with the smallest defect density) and (ii) the dissolution rate normalized to the initial surface area is increased by a 3-fold factor. Importantly, the dissolution rate does not linearly increase with the defect density, as can be seen from the mitigation of the effect of defect density on the dissolution rate (Fig. 11a). This modeling result follows from the combination of two main features: (1) the rapid coalescence of etch pits, which prevents the surface area of pit walls from reaching an elevated proportion of the total surface area and (2) the orientation of the bottom of the pits, which is parallel to the (001) surface, such that their reactivity is identical to that of the top surface. In addition, this output of our numerical simulation is in agreement with experimental studies which showed that increasing the dislocation density has a minor effect on the dissolution rate: for instance, it has been reported that increasing the dislocation density of minerals by up to four orders of magnitude results in a maximal increase of the dissolution rate by a 14-fold factor (Blum et al., 1990; Casey et al., 1988a,b; MacInnis and Brantley, 1992; Murphy, 1989; Schott et al., 1989).

The length of the dislocation line parallel to the $z$ direction seems to have a more dramatic impact on dissolution (see Figs. 10d-f and Fig. 11b), possibly stemming from the 
fact that at each time step, the proportion of etch pits that are flat-bottomed is considerably smaller when $l_{d}$ is greater. If $l_{d}$ is increased by a 100 -fold factor, the surface area is increased by approximately $60 \%$, and the dissolution rate is about 5 times faster, although straight dislocation lines of several tens of microns are probably unlikely in most minerals. It should also be noted that when the dislocation line is small $\left(l_{d}<0.2 \mu \mathrm{m}\right)$, the surface area never reaches a steady state over the course of the reaction progress. However, the surface area increase is limited $(\leq 10 \%)$ and impacts negligibly the dissolution rate of the face.

Finally, when the $k_{d}$ parameter is multiplied by 6 , we observe a decrease of $10 \%$ for the surface area and of 58\% for the dissolution rate $R$. The dissolution rate $R$ varies between $\sim 1.6 \times 10^{-8}$ and $\sim 3.7 \times 10^{-8} \mathrm{~mol} . \mathrm{m}^{-2} \cdot \mathrm{s}^{-1}$. This range of variation is of second order compared to other factors such as the dissolution rate measurement uncertainties.

Overall, these sensitivity tests illustrate that the specific physical characteristics of the defects (size, density and reactivity) which populate minerals do impact mineral dissolution rates, and probably contribute to the dispersion of rate data that have been reported in the literature (e.g. Fischer et al., 2014). However, if the dissolution of the (001) orthoclase face is considered as an appropriate model for the dissolution behavior of feldspars as a whole, the combined effect of all of the above-described parameters do not affect the dissolution rate by more than an order of magnitude (Fig. 12), which remains relatively limited.

\section{CONCLUSION}

The present study brought new experimental and modeling constraints on the impact of etch pits on the dissolution rate of the (001) orthoclase surface. The main results include: (i) the attainment of a steady-state surface area, in spite of the continuous nucleation and growth of etch pits, (ii) the determination of the overestimation of the (001) surface reactivity due to normalization of the data to the initial surface area, (iii) the greater reactivity of pit 
walls compared to the (001) surface, and (iv) the limited effect of dislocation density on the dissolution rate. In addition, the characterization of the crystallographic orientation of pit walls likely explained their greater intrinsic reactivity. Such geometric characterizations may provide useful data to assess the accuracy of more sophisticated models based on firstprinciples, such as kinetic Monte Carlo simulations (e.g. Kurganskaya and Lüttge, 2013a,b) which should be able to improve upon some shortcomings of the present study, such as the lack of a unified function that relates the empirical parameter $k_{x}$ to $k_{y}$ and $k_{z}$.

Although the effect of dislocations remained modest in the present case, it is worth reminding that highly deformed minerals may have dislocation densities that are up to 6 orders of magnitude greater than that of the sample that we used. In this case, the impact of pitting can be greater, and may contribute to the dispersion of rate data that have been reported in the literature.

\section{ACKNOWLEDGMENTS}

This work has been funded through a grant attributed to D.D. for the project "Feldspar reactivity in the context of Soultz-sous-Forêts: From microstructural characterizations to numerical modeling" under the framework of the LABEX ANR-11-LABX-0050_G-EAUTHERMIE-PROFONDE which benefits from a funding from the state managed by the French National Research Agency as part of the French "Investissements d'avenir". M.P.-V. thanks the Région Alsace and LABEX “G-EAU-THERMIE PROFONDE” for funding her PhD contract. K.G.K. effort at LBL was supported by the Director, Office of Science, Office of Basic Energy Sciences, Chemical Sciences, Geosciences, and Biosciences Division, of the U.S. Department of Energy under Contract No. DE-AC02-05CH11231. 
Thanks are due to R. Boutin, G. Morvan, A. Aubert and M. Mombru for their help with analyses and technical contributions at the LHyGeS (Strasbourg, France). We also thank G. A. Waychunas (LBNL Berkeley, USA) for providing us the K-spar crystal used to carry out this study, A. Clément (LHyGeS, Strasbourg, France) for providing high-performance computer and G. D. Saldi (LBNL Berkeley, USA) for his help with dissolution experiments. The careful revisions and insightful suggestions by 3 anonymous reviewers helped clarify and improve an earlier version of this work. 


\section{RERFERENCES CITED}

Amelinckx, S. 1964. The direct observation of dislocations. Solid State Physics, suppl., 6, 487.

Arvidson, R. S., Ertan, I. E., Amonette, J. E., and Lüttge A., 2003. Rates of calcite dissolution obtained by vertical scanning interferometry. Geochim. Cosmochim. Ac., 67, 16231634.

Beig, M. S. and Luttge, A., 2006. Albite dissolution kinetics as a function of distance from equilibrium: Implications for natural feldspar weathering. Geochim. Cosmochim. Ac., $70,1402-1420$.

Berner, R. A., Sjöberg, E. L., Velbel, M. A., and Krom, M. D., 1980. Dissolution of pyroxenes and amphiboles during weathering. Science, 207, issue 4436, 1205-1206.

Blum, A. E., Yund, R. A. and Lasaga, A. C., 1990. The effect of dislocation density on the dissolution rate of quartz. Geochim. Cosmochim. Ac., 54, 283-297.

Bandstra, J.Z., Brantley, S.L., 2008. Surface evolution of dissolving minerals investigated with a kinetic Ising model. Geochim. Cosmochim. Ac. 72, 2587-2600.

Brantley, S. L., Crane, S. R., Crerar, D. A., Hellmann, R., and Stallard, R., 1986. Dissolution at dislocation etch pits in quartz. Geochim. Cosmochim. Ac., 50, 2349 - 2361.

Brantley, S. L. and Chen, Y. 1995. Chemical weathering rates of pyroxenes and amphiboles. In Chemical Weathering Rates of Silicate Minerals, Vol. 31 (ed. A. F. With and S. L. Brantley), 119-172. Mineralogical Society of America.

Brantley, S. L., Kubicki J. and White A. F., 2008. Kinetics of Water-Rock Interaction. Springer, New York.

Casey, W. H., and Carr M. J. and Graham R. A.,1988a. Crystal defects and the dissolution kinetics of rutile. Geochim. Cosmochim. Ac., 52, 1545-1556. 
Casey, W. H., Westrich, H. R. and Arnold, G. W., 1988b. Surface Chemistry of labradorite Feldspar reacted with aqueous solutions at $\mathrm{pH}=2,3$ and 12. Geochim. Cosmochim. Ac., 52, 2795-2807.

Colville, A. A. and Ribbe, P. H., 1968. The crystal structure of an adularia and a refinement of the structure of orthoclase. Am. Mineral., 53, 25-37.

Cressie, N. A. C., 1993. Statistics for spatial data. Wiley Series in Probabililty and Statistics. Wiley Classics Library.

Daval, D., Testemale, D., Recham, N., Tarascon, J.-M., Siebert, J., Martinez, I., Guyot, F., 2010. Fayalite $\left(\mathrm{Fe}_{2} \mathrm{SiO}_{4}\right)$ dissolution kinetics determined by X-ray absorption spectroscopy. Chem. Geol., 275, 161-175.

Daval, D., Hellmann, R., Saldi, G. D., Wirth, R. and Knauss, K. G., 2013. Linking nm-scale measurements of the anisotropy of silicate surface reactivity to macroscopic dissolution rate laws: New insights based on diopside. Geochim. Cosmochim. Ac., 107, 121-134.

Duckworth, O. W. and Martin, S. T., 2004. Dissolution rates and pit morphologies of rhombohedral carbonate minerals. Am. Mineral., 89, 554-563.

Fenter, P., Cheng, L., Park, C., Zhang, Z. and Sturchio, N. C., 2003. Structure of the orthoclase (001)- and (010)-water interfaces by high-resolution X-ray reflectivity. Geochim. Cosmochim. Ac., 67, 22, pp. 4267-4275.

Fenter, P., Zapol, P., He, H. and Sturchio, N. C., 2014. On the variation of dissolution rates at the orthoclase $\left(\begin{array}{lll}0 & 0 & 1\end{array}\right)$ surface with $\mathrm{pH}$ and temperature. Geochim. Cosmochim. Ac.141, 598-611.

Fischer, C., Kurganskaya, I., Schäfer, T., Lüttge, A., 2014. Variability of crystal surface reactivity: What do we know? Appl Geochem, 43, 132-157. 
Fritz, B., Jacquot, E., Jacquemont, B., Baldeyrou-Bailly, A., Rosener, M. and Vidal, O. 2010. Geochemical modelling of fluid-rock interactions in the context of the Soultz-sousForets geothermal system. C.R. Geosci., 342, 653-667.

Gautier, J.M., Oelkers, E.H., Schott, J., 1994. Experimental study of K-feldspar dissolution rates as a function of chemical affinity ar $150^{\circ} \mathrm{C}$ and $\mathrm{pH}$ 9. Geochim. Cosmochim. Ac. $58,4549-4560$.

Gautier J-M., Oelkers E. H. and Schott J., 2001. Are quartz dissolution rates proportional to B.E.T. surface areas? Geochim. Cosmochim. Ac., 65, 1059-1070.

Godinho, J. R. A., Piazolo, S. \& Evins, L. Z., 2012. Effect of surface orientation on dissolution rates and topography of $\mathrm{CaF}_{2}$. Geochim. Cosmochim. Ac., 86, 392-403.

Godinho, J.R.A., Piazolo, S. and Balic-Zunic, T., 2014. Importance of surface structure on dissolution of fluorite: Implications for surface dynamics and dissolution rates. Geochim. Cosmochim. Ac.126, 398-410.

Golubev, S. V. and Pokrovsky, O. S., 2006. Experimental study of the effect of organic ligands on diopside dissolution kinetics. Chem. Geol., 377-389.

Gratz, A. J. and Bird, P., 1993. Quartz dissolution: negative crystal experiments and a rate law. Geochim. Cosmochim. Ac., 57, 965-976.

Hartman, P., Perdok, W.G., 1955. On the relations between structure and morphology of crystals. I. Acta Crystallographica 8, 49-52.

Hellmann, R., 1997. The albite-water system: Part IV. Diffusion modeling of leached and hydrogen-enriched layers. Geochim. Cosmochim. Ac., 61, 1595-1611.

Holdren, G. R. J., Casey, W. H., Westrich, H. R., Carr, M. J. and Boslough, M., 1988. Bulk dislocation densities and dissolution rate in calcic plagioclase. Chem. Geol., 70, 79-85. 
Knauss, K. G., Johnson, J. W. and Steefel, C. I., 2005. Evaluation of the impact of $\mathrm{CO}_{2}$, cocontaminant gas, aqueous fluid and reservoir rock interactions on the geologic sequestration of CO2. Chem. Geol., 217, 339-350.

Kurganskaya, I. and Lüttge, A., 2013. A comprehensive stochastic model of phyllosilicate dissolution: Structure andkinematics of etch pits formed on muscovite basal face. Geochim. Cosmochim. Ac., 120, 545-560.

Kurganskaya, I and Lüttge, A., 2013. Kinetic Monte Carlo Simulations of Silicate Dissolution: Model Complexity and Parametrization, J. Phys. Che. C, 117, 2489424906.

Lasaga, A. C. and Blum, A. E., 1986. Surface chemistry, etch pits andmineral-water reaction. Geochim. Cosmochim. Ac., 50, 2363-2379.

Lasaga, A. C. and Luttge, A., 2001. Variation of Crystal Dissolution Rate Based on a Dissolution Stepwave Model. Science291, 2400-2404.

Lucca, D. A., Shao, L., Wetteland, C. J., Misra, A., Klopfstein, M. J. and Nastasi, M., 2006. Subsurface damage in (100) ZnSe introduced by mechanical polishing. Nuclear Instruments \& Methods in Physics Research, Section B., 249, 907-910.

Lüttge A., 2005. Etch pit coalscence, surface area, and overall mineral dissolution rates. Am. Mineral., 90, 1776-1783.

MacInnis, I. N. and Brantley, S. L., 1992. The role of dislocations and surface morphology in calcite dissolution. Geochim. Cosmochim. Ac., 56, 1113-1126.

MacInnis, I. N. and Brantley, S. L., 1993. Development of etch pit size distribution on dissolving minerals. Chem. Geol., 105, 31-49.

Maher, K. and Chamberlain, C. P., 2014. Hydrologic Regulation of Chemical Weathering and the Geologic Carbon Cycle. Science, 343, 1502-1504. 
Marshall, D. B. and McLaren, A. C., 1977. Deformation mechanisms in experimentally deformed plagioclase feldspars Physics and Chemistry of Minerals, 1, 351-370.

Meakin, P. and Rosso, K. M., 2008. Simple kinetic Monte Carlo models for dissolution pitting induced by crystal defects. The journeal of chemical physics, 129, 204-106.

Murphy, W. M., 1989. Dislocations and Feldspar dissolution Euro. J. Mineral, 1, 315-326.

Nicoleau, L. and Bertolim, M. A., 2015. Analytical Model for the Alite (C3S) Dissolution Topography. J. Am. Ceram. Soc., 99, 773-786.

Olsen, T. S. and Kohlstedt, D. L., 1984. Analysis of dislocations in some naturally deformed plagioclase feldspars. Physics and Chemistry of Minerals, 11, 153-160.

Pollet-Villard, M., Daval, D., Ackerer, P., Saldi, G. D., Wild, B., Knauss, K. G. and Fritz, B., (2016). Does crystallographic anisotropy prevent the conventional treatment of aqueous mineral reactivity? A case study based on K-feldspar dissolution kinetics. Geochim. Cosmochim. Ac., 190, 294-308.

Schott, J., Brantley, S., Crerar, D., Guy, C., Borcsik, M. and Willaime, C., 1989. Dissolution kinetics of strained calcite. Geochim. Cosmochim. Ac., 53, 373 - 382.

Scislewski, A. and Zuddas, P., 2010. Estimation of reactive mineral surface area during waterrock interaction using fluid chemical data. Geochim. Cosmochim. Ac.,74, 6996-7007.

Smith, M. E., Knauss K. G. and Higgins S. R., 2013. Effects of crystal orientation on the dissolution of calcite by chemical and microscopic analysis. Chem. Geol., 360-361, 1021.

Teng, H. H., Fenter P., Cheng, L., and Sturchio, N. C., 2001. Resolving orthoclase dissolution processes with atomic force microscopy and X-ray reflectivity. Geochim. Cosmochim. Ac., 65, 20, pp. 3459-3474.

Van der Lee, J. and De Windt L., 2002. CHESS Tutorial and Cookbook. Updated for version 3.0, Manual Nr. LHM/RD/02/13, Paris, 116 pp. 
White, A. F. and Brantley, S. L. Eds, 1995. Chemical weathering rates of silicate minerals, 31, 583 pp. Reviews in Mineralogy, Mineralogical Society of America, Chantilly, Virginia.

Willaime, C. and Gandais, M., 1977. Electron microscope study of plastic defects in experimentally deformed alkali feldspars. Bull. Soc. Fr. Mineral. Cristall. 100, 263-271. Woensdregt, C.F., 1982. Crystal morphology of monoclinic potassium feldspar: a qualitative approach with special emphasis on the Periodic Bond Chain Theory of Hartman and Perdrok. Zeitschrift für Kristallographie, 161, 15-33.

Yund, R. A., Smith, B. M. and Tullis, J., 1981. Dislocation-assisted diffusion of oxygen in albite Physics and Chemistry of Minerals, 7, 185-189.

\section{FIGURE LEGENDS:}

Fig. 1: Face-specific dissolution experiments on orthoclase samples. (a) K-feldspar sample $\left(7.5 \times 3 \times 3 \mathrm{~mm}^{3}\right)$ mounted in a titanium support as designed by Daval et al., 2013. A Viton® disk held with a screw creates a non-wetted reference area. The crystal is subsequently altered in a mixed-flow reactor (b) at $180^{\circ} \mathrm{C}$ in a synthetic alkaline solution $\left(\mathrm{pH}_{180^{\circ}} \mathrm{C}=9.0\right)$ during 4.8 days.

Fig. 2: Typical 3D-view of etch pits formed on the (001) orthoclase-face after 2.21 days of reaction as imaged by AFM. Etch pits have a diamond shape with diagonals parallel to the [100] and [010] axes.

Fig. 3: Evolution of etch pit morphology over the course of the dissolution of the (001)orthoclase face at $\mathrm{pH} 9$ and $180^{\circ} \mathrm{C}$, at far-from-equilibrium conditions.(a) $\alpha$ and $\beta$ angles 
between two contiguous etch pit edges in the (001) plane. The measurements showed that the angle values $\left(63 \pm 5^{\circ}\right.$ and $\left.121 \pm 5^{\circ}\right)$ are constant during the reaction process. (b) Measured angles between the (001) plane and etch pit walls. The measurements were carried out on sections perpendicular to the pit edges (dashed line on the etch pit schematic reported in Fig. 3a). The $\gamma$ angle reached a constant value of $27 \pm 5^{\circ}$ after two days of reaction. (c) Typical examples of depth evolution over time for three etch pits (A, B and C). The etch pit depth reached a constant value. This value is etch pit-dependent. The measurements were carried out on approximatively 50 etch pits; error bars correspond to the standard deviation.

Fig. 4: Evolution of the etch pit geometry and the surface retreat of the (001) surface over time. Black points represent the experimental data and grey points the results of numerical modelling. (a) Etch pit illustration with the definition of the surface retreat $\Delta h(\mu \mathrm{m})$, the length $L$ and the width $l(\mu \mathrm{m})$ of etch pits. (b) Surface retreat $\Delta h(\mu \mathrm{m})$ as a function of time. $\Delta h$ measurements were carried out on VSI images in stitching mode. (b) Average length $L$ $(\mu \mathrm{m})$ and $(\mathrm{c})$ width $l(\mu \mathrm{m})$ evolution of the etch pits. Measurements were carried out on approximatively fifty etch pits monitored by AFM. Error bars represent the data standard deviation.

Fig. 5: Evolution of the (001) orthoclase surface topography over the course of the dissolution process. (a) AFM images in deflection mode $\left(100 \times 100 \mu \mathrm{m}^{2}\right)$ of the surface evolution after $0.75,1.56,2.21$ and 4.80 days of alteration. The images show the nucleation and growth of etch pits during the dissolution experiment carried out at $180^{\circ} \mathrm{C}$ in an alkaline solution $\left(\mathrm{pH}_{180^{\circ} \mathrm{C}}=9\right)$. (b) Numerical simulation of the $(001)$ surface evolution. See text for details. 
Fig. 6: Comparison of variograms calculated on the actual (black squares) and modelled (light and dark grey) surface topography of the (001) cleavage surface at four time steps throughout the dissolution progress. Light grey symbols correspond to the variograms calculated on a perfectly flat surface. Dark grey symbols correspond to the variogram calculated on a slightly rounded surface (see text for details). The dashed line indicates the correlation length (i.e. the typical size of etch pits). The insert in graph (d) presents the variance of the surface topography calculated on the modeled surface as a function of the variance of the surface topography calculated on the surface monitored experimentally. This figure illustrates that the experimental data and the numerical simulations are statistically equivalent.

Fig. 7: Typical AFM image of a $100 \times 100 \mu \mathrm{m}^{2}$ surface of orthoclase after 0.75 day of alteration at $180^{\circ} \mathrm{C}$, highlighting the global rounding of the surface resulting from polishing.

Fig. 8: Modeled surface area and dissolution rate evolution during the dissolution process. (a), (c) Evolution of the ratio of the current surface area $S(t)$ to the initial surface area $S\left(t_{0}\right)$ of the (001) face as a function of the reaction progress (\%) for volumes $V_{1}\left(100 \times 100 \times 4 \mu m^{3}\right)$ and $V_{2}$ $\left(200 \times 200 \times 20 \mu \mathrm{m}^{3}\right)$. (b), (d) Evolution of the dissolution rate $\left(\mathrm{mol} \cdot \mathrm{m}^{2} \cdot \mathrm{s}^{-1}\right)$ normalized to the initial surface area $S\left(t_{0}\right)$ (black squares) or current surface area $S(t)$ (grey squares) for $V_{1}$ and $V_{2}$ volumes. The dashed lines represent the expected dissolution rate for a surface devoid of etch pits.

Fig. 9: Intrinsic pit wall dissolution rate. Pit walls dissolve one order of magnitude faster than the (001) surface. 
Fig. 10: Influence of defect parameters on surface and dissolution rate evolution. Graphs (a), (b) and (c) present respectively the ratio $S(t) / S\left(t_{0}\right)$, the dissolution rate $R$ calculated with respect to $S(t)$ and the dissolution rate $R_{0}$ calculated with respect to $S\left(t_{0}\right)$ as a function of the reaction progress for different defect densities $\left(d_{s}\right.$ and $\left.d_{v}\right)$. In figures (d), (e) and (f) we observe $\mathrm{S}(\mathrm{t}) / \mathrm{S}\left(\mathrm{t}_{0}\right)$ and $\mathrm{R}$ variations for three different maximal lengths of dislocation lines parallel to the $z$ direction $\left(l_{d}\right)$. The graphs $(\mathrm{g})$, (h) and (i) show the effect of defect dissolution rate $\left(k_{d}\right.$ parameter $)$ on the surface and the dissolution rate evolution.

Fig. 11: Dissolution rate evolution as a function of defects densities $d_{s}+d_{v}$, maximal defect line length $l_{d}^{\max }$ and defect dissolution rate parameter $k_{d}$.

Fig. 12: Combined effect of defect density $\left(d_{s}\right.$ and $\left.d_{v}\right)$, maximal defect length $\left(l_{d}\right)$ lines and defect dissolution rate ( $k_{d}$ parameter). Graphs (a) and (b) represent respectively the surface evolution and the dissolution rates as a function of the reaction progress calculated for $d_{s}=$ $2 \times 10^{6}$ defects.cm ${ }^{-2}, d_{v}=3 \times 10^{5}$ defects.cm ${ }^{-2}, l_{d}^{\max }=20 \mu \mathrm{m}$ and $k_{d}=1$. Graphs (c) and (d) represent also the surface area and dissolution rates as a function of the reaction progress, for $d_{s}=2 \times 10^{4}$ defects.cm ${ }^{-2}, d_{v}=3 \times 10^{3}$ defects. $\mathrm{cm}^{-2}, l_{d}^{\max }=0.2 \mu \mathrm{m}$ and $k_{d}=6$. 


\section{TABLES}

\begin{tabular}{ccccccccccc}
\hline & $\mathbf{S i O}_{2}$ & $\mathbf{A l}_{2} \mathbf{O}_{3}$ & $\mathbf{M g O}$ & $\mathbf{C a O}$ & $\mathbf{F e}_{2} \mathbf{O}_{3}$ & $\mathbf{M n O}$ & $\mathbf{T i O}_{2}$ & $\mathbf{N a}_{2} \mathbf{O}$ & $\mathbf{K}_{2} \mathbf{O}$ & Total \\
\hline Weight (\%) & 66.1 & 18.2 & 0.022 & 0.075 & 0.11 & 0.0016 & 0.009 & 1.76 & 12.8 & 99.1 \\
\hline
\end{tabular}

Table 1: Major element abundances in orthoclase mineral measured by Inductively Coupled Plasma Atomic Emission Spectroscopy (ICP-AES; THERMO ICAP 6000 Series) after standard digestion procedure at the LHyGeS (Strasbourg, France). Weight percentage of dried sample at $110^{\circ} \mathrm{C}$.

\begin{tabular}{|c|c|c|c|c|c|c|c|c|c|c|}
\hline \multirow[b]{2}{*}{ Expt. } & \multirow[b]{2}{*}{$\begin{array}{c}\mathbf{t} \\
\text { (days) }\end{array}$} & \multirow{2}{*}{$\begin{array}{c}v \\
(\mathrm{~mL} / \mathrm{min})\end{array}$} & \multirow{2}{*}{$\begin{array}{c}\mathbf{p H}_{\text {in situ }} \\
{ }_{180^{\circ} \mathrm{C}}\end{array}$} & \multicolumn{5}{|c|}{ Concentrations out (ppm) } & \multirow{2}{*}{ 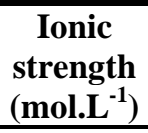 } & \multirow{2}{*}{$\begin{array}{c}\Delta G_{r} \\
(\mathbf{k J} / \mathbf{m o l})\end{array}$} \\
\hline & & & & {$[\mathrm{Si}]$} & {$[\mathrm{Al}]$} & {$[\mathbf{K}]$} & {$[\mathrm{Na}]$} & {$[\mathrm{Cl}]$} & & \\
\hline MRGT1 & 4.8 & 0.20 & 9.0 & 0.25 & 3.99 & 0.12 & 114.96 & 12.82 & $4.99 \mathrm{E}-03$ & -89 \\
\hline
\end{tabular}

Table 2: Summary of experimental and calculated aqueous data of (001) orthoclase

dissolution experiment. Columns 1-4 indicate: the name of experiment, the total time duration of experiment (days), the flow-rate $v$ of the pump $(\mathrm{mL} / \mathrm{min})$ and the $\mathrm{pH}_{\text {in situ }}$ calculated with the $\mathrm{CHESS}^{\circledR}$ code. The in situ solution compositions (in ppm) are listed in the five next columns. Fluid concentration measurements, excepted for [Cl], were carried out with ICPAES. The two last columns present the ionic strength (mol.L $\left.{ }^{-1}\right)$ of the solution and the $\Delta G_{r}$ $\left(\mathrm{kJ} \cdot \mathrm{mol}^{-1}\right)$ value with respect to K-feldspar dissolution calculated using $\mathrm{CHESS}^{\circledR}$. 


\begin{tabular}{lllll}
\hline & $\boldsymbol{x}$ & $\boldsymbol{y}$ & $\boldsymbol{z}$ \\
\hline EC edges length $(\boldsymbol{\mu m})$ & 0.2 & 0.2 & 0.05 \\
Dissolution period $\boldsymbol{k}_{\boldsymbol{i}}$ & & 3 & 2 & 10 \\
& $\mathrm{~V}_{\mathbf{1}}$ & 500 & 500 & 80 \\
Number of cells & $\mathbf{V}_{\mathbf{2}}$ & 1000 & 1000 & 400 \\
\hline
\end{tabular}

Table 3: Numerical model parameters. The table lists the dimensions of the ECs edges, the dissolution period $k_{i}$ and the number of cells in the $x, y$ and $z$ directions. $V_{1}$ and $V_{2}$ correspond to two different initial sample volumes which were used for the simulations. Note that for all simulations, $k_{d}$ was set equal to 2 , in agreement with the observed evolution of the (001) surface. 


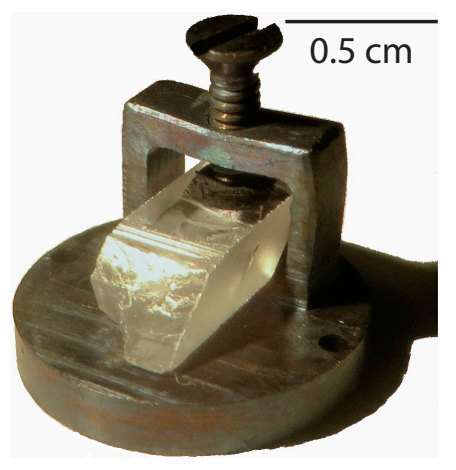

(b)

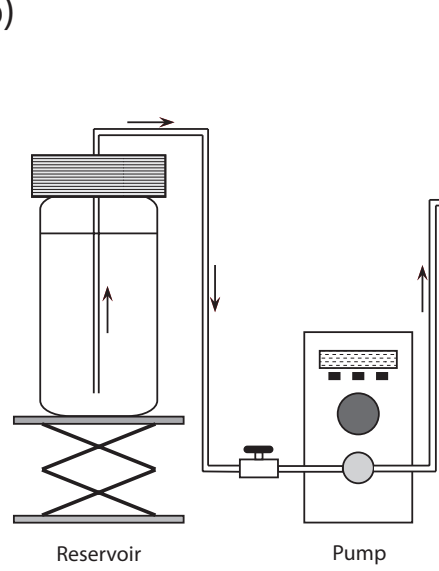

Magnetic stirrer

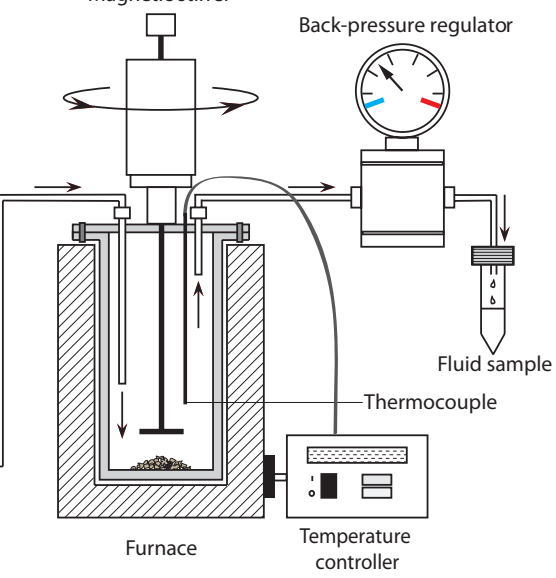


Figure $\mu \mathrm{m}$
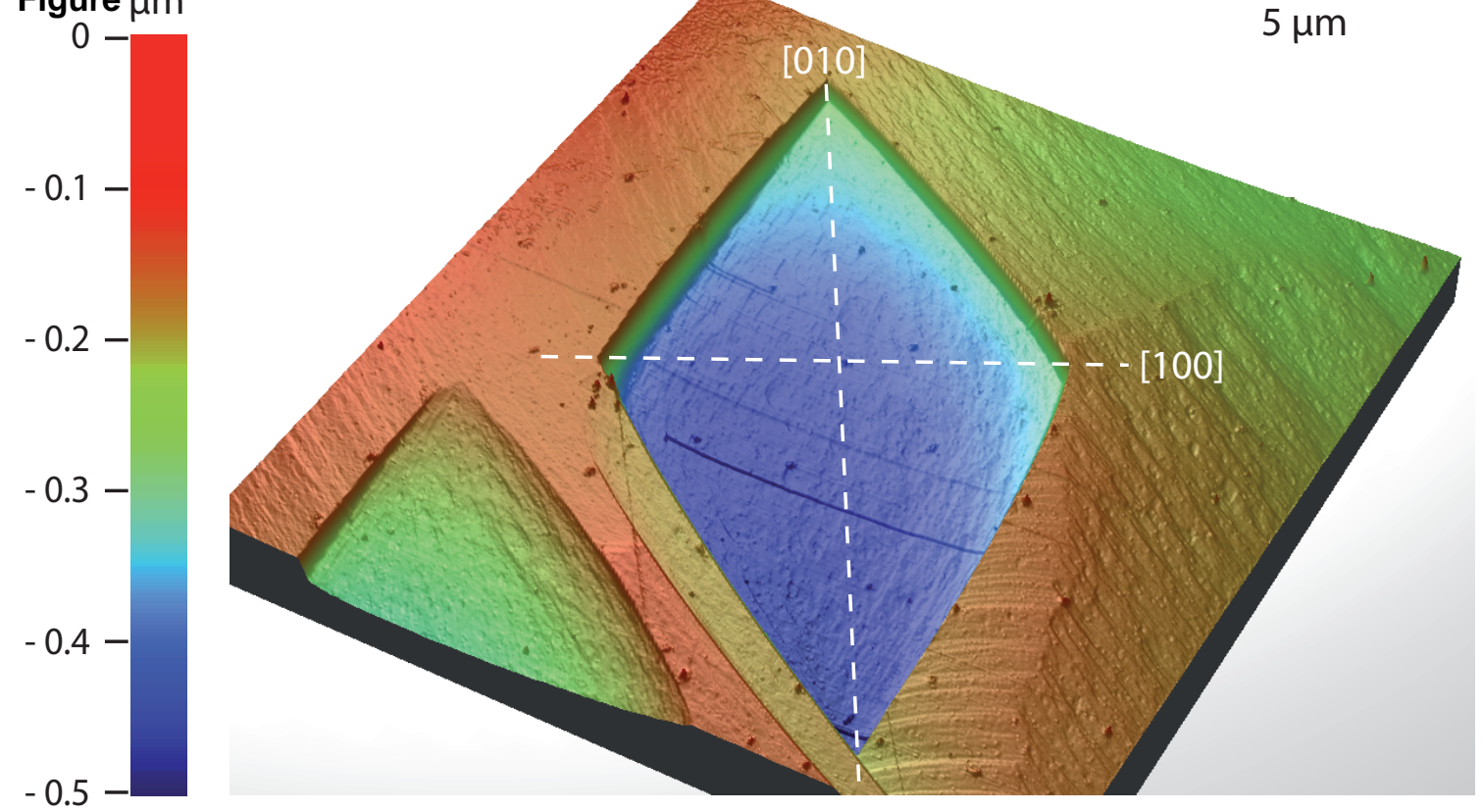


\section{Faigure}
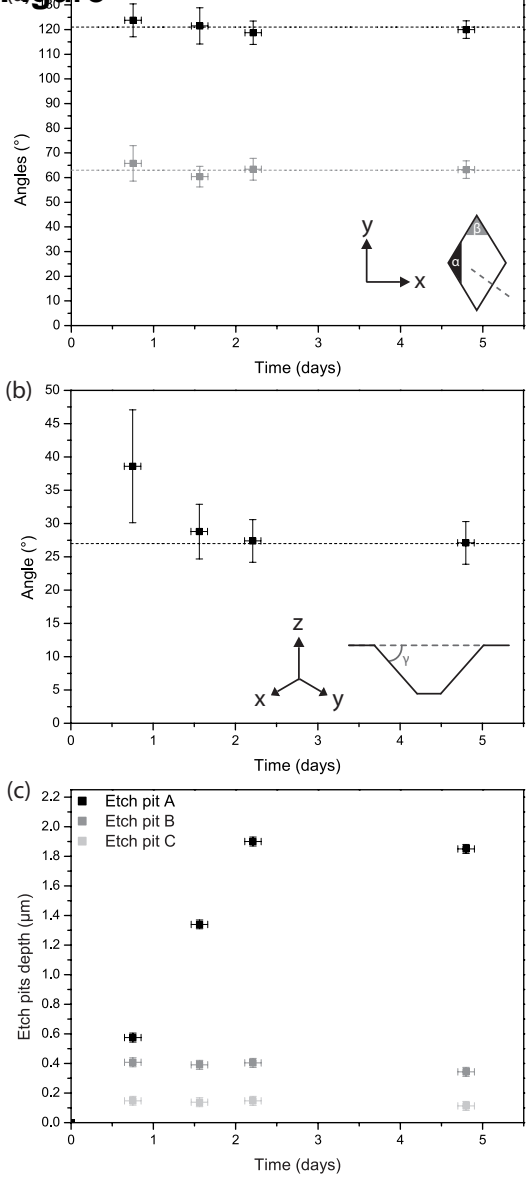
Figgure
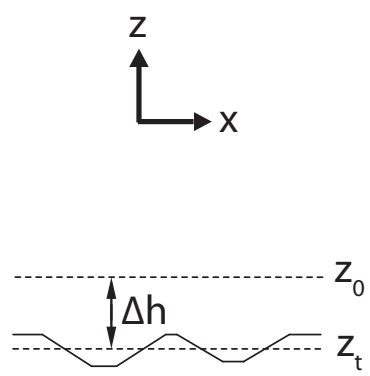

(c)
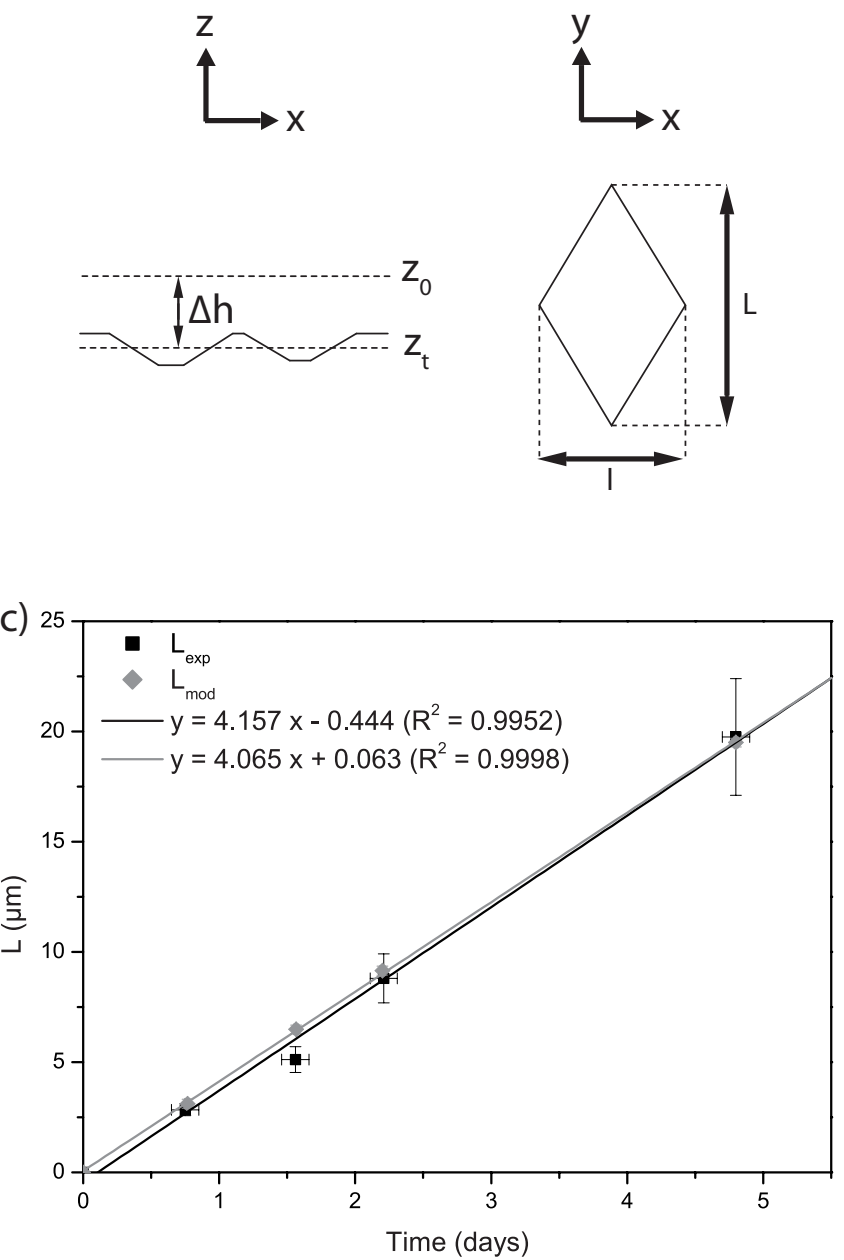

(b)

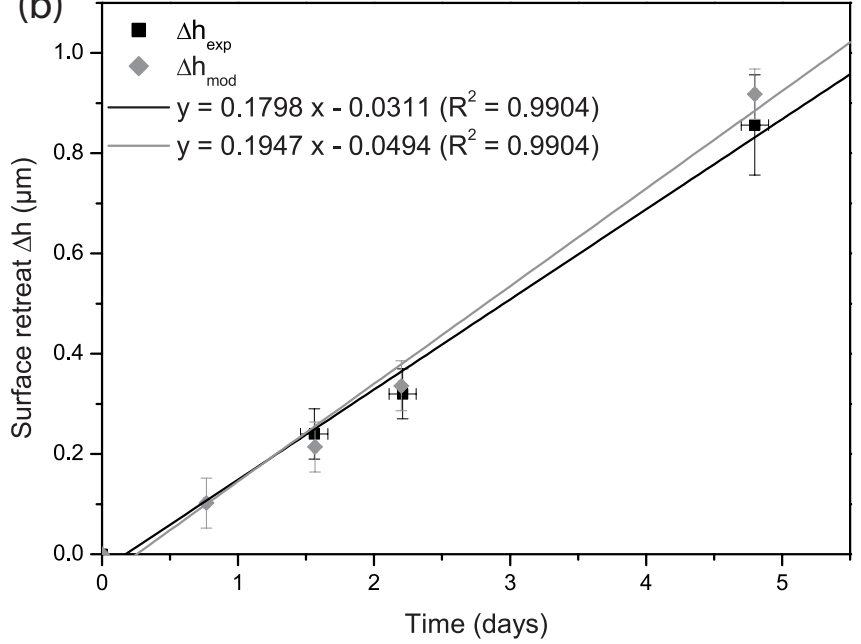

(d)

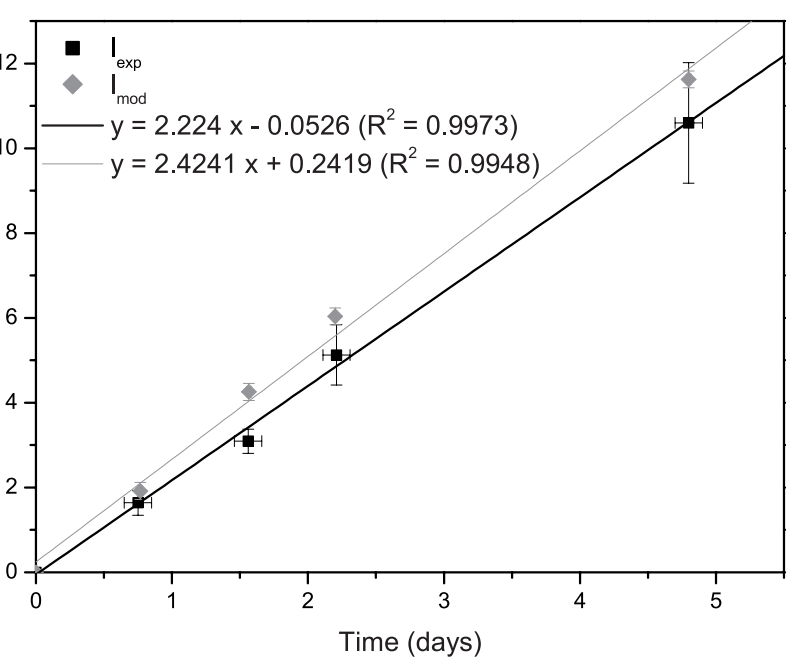




\section{Figure. $75 \mathrm{~d}$}

$\overline{25 \mu \mathrm{m}}$

(b)

Time (days): 0.765900

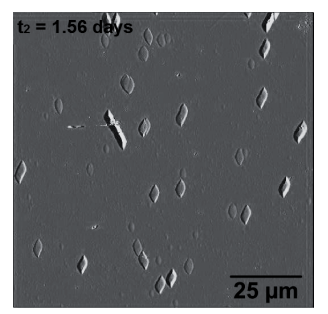

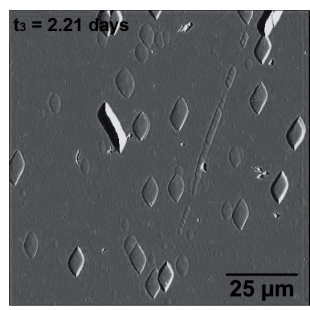

Time (days): 1.565100

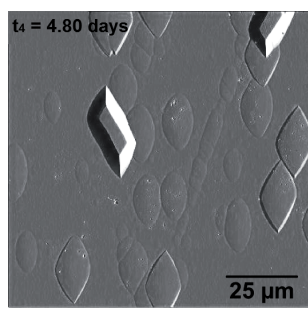

Time (days): 4.795200

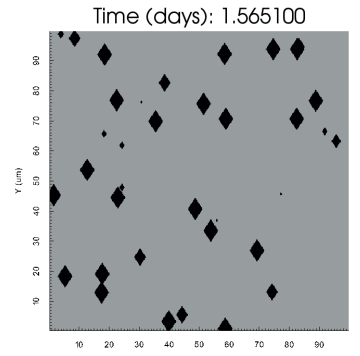

Time (days): 2.197800

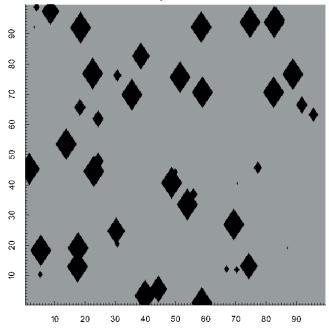

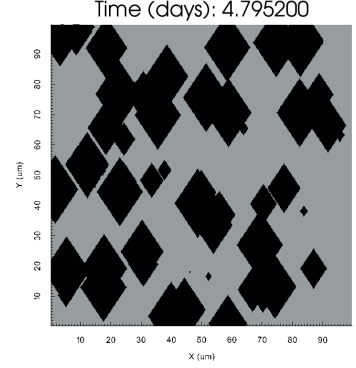


Figure

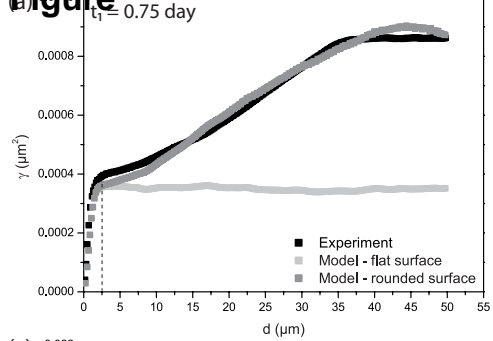

(c)

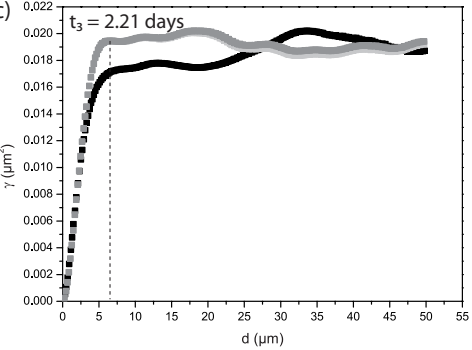

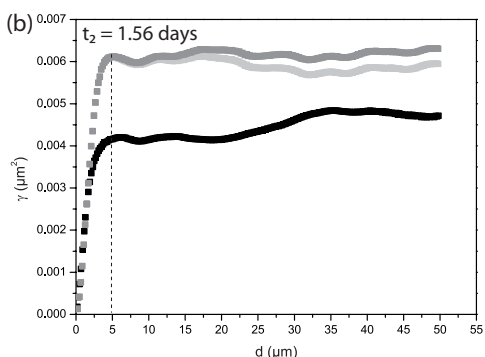

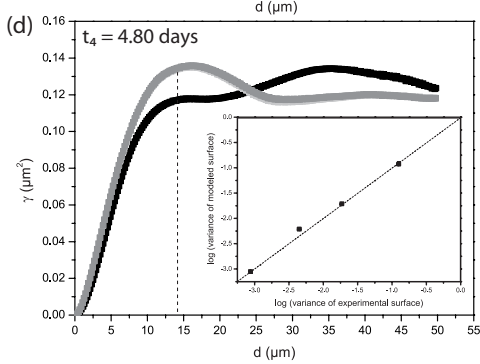


Figure

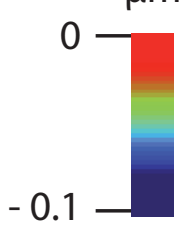

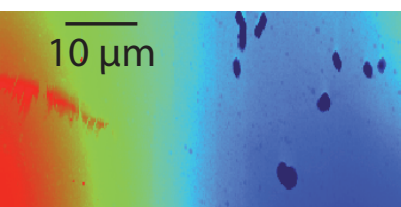

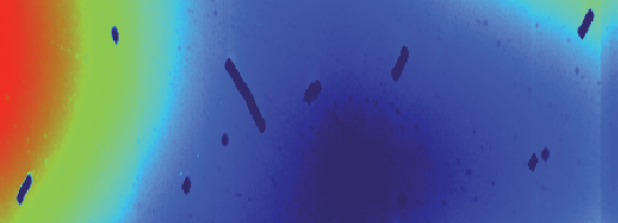

, 


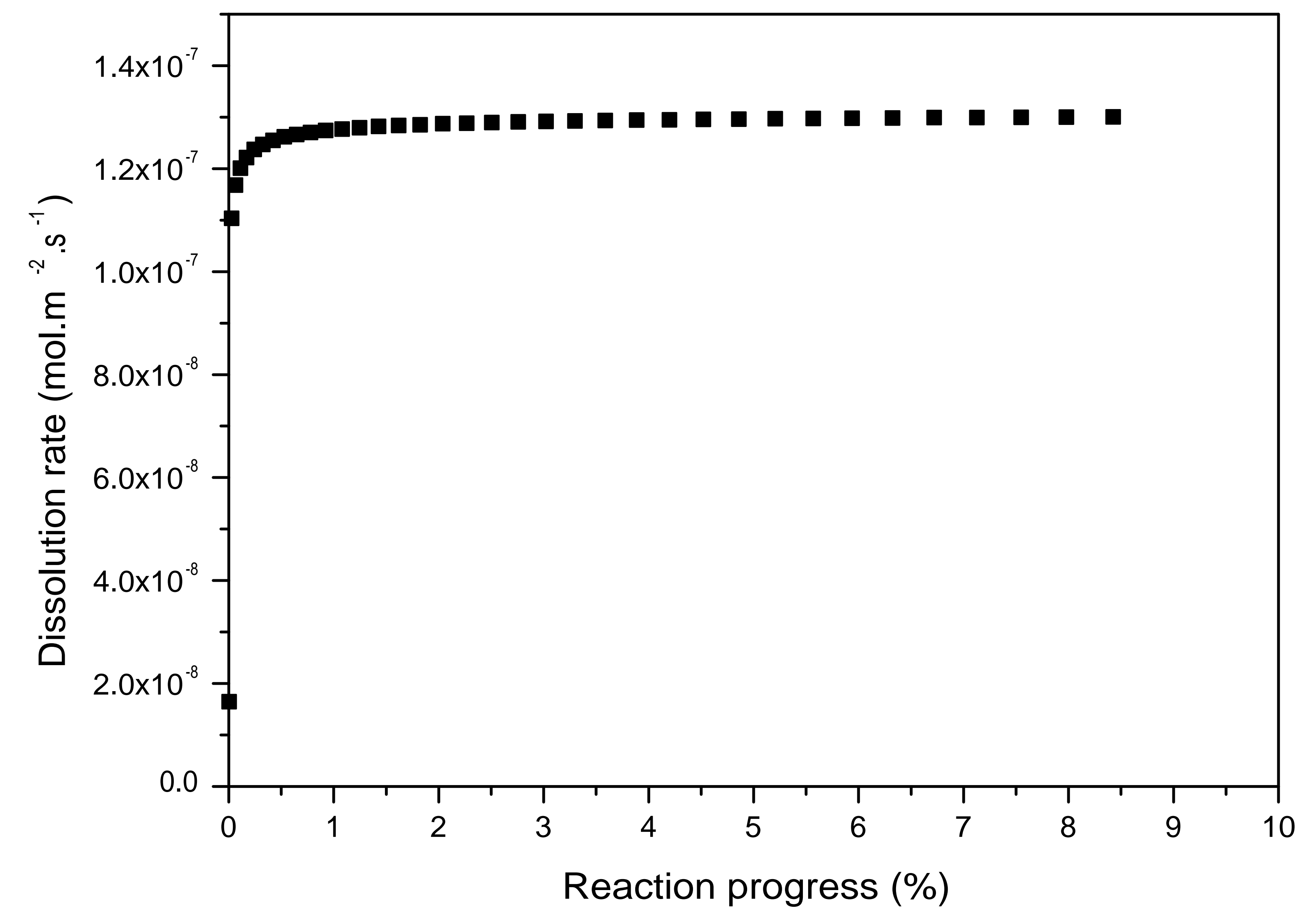




\section{(Figure}

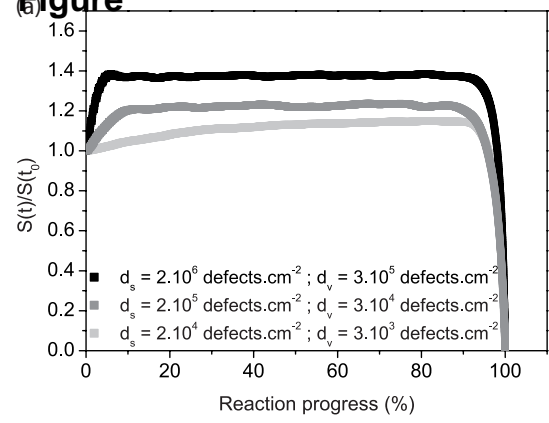

(d)

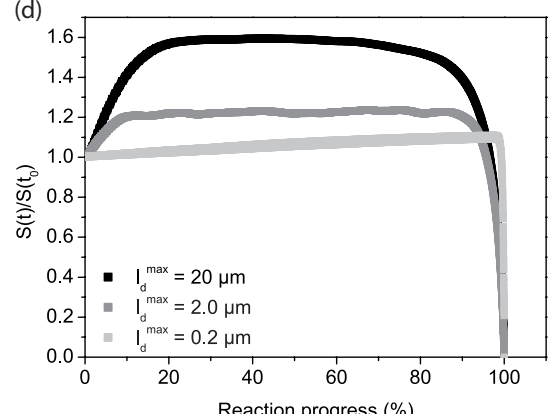

(g)

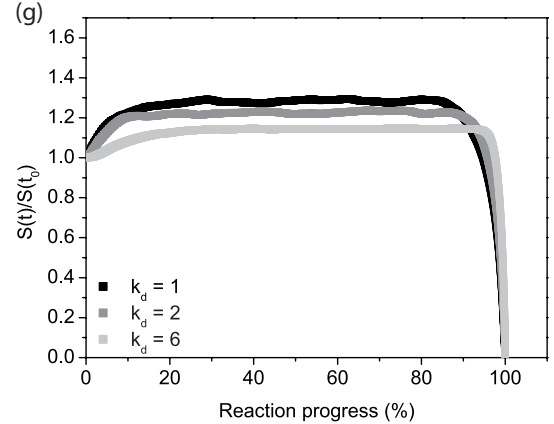

(b)

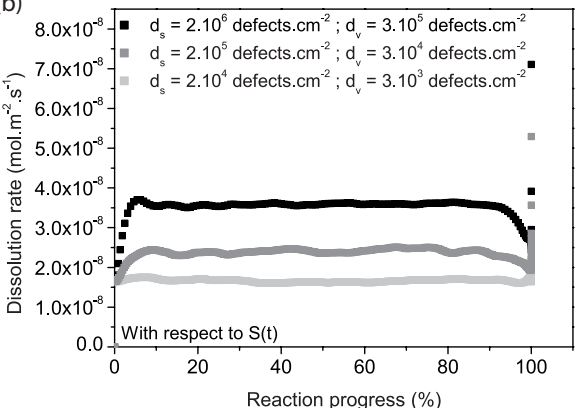

(e)

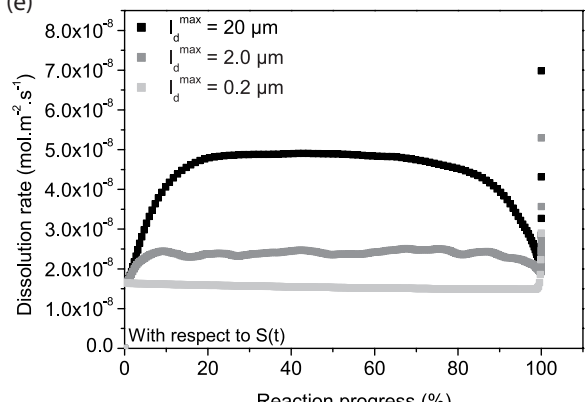

(h)

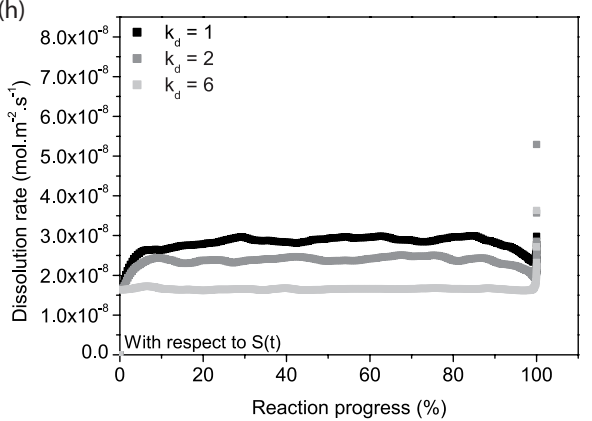

(c) $8.0 \times 10^{-8}-d=2.10^{6}$ defects. $\mathrm{cm}^{-2} ; d=3.10^{5}$ defects. $\mathrm{cm}^{-2}$

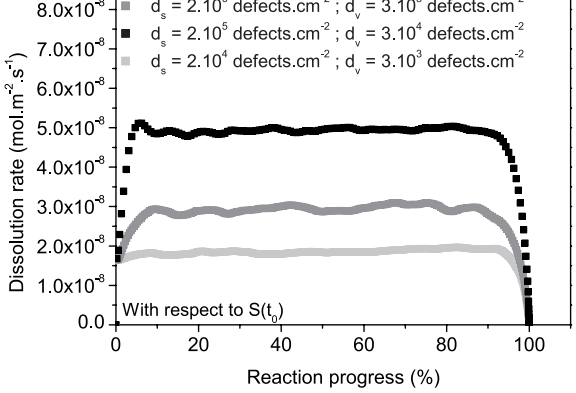

(f)

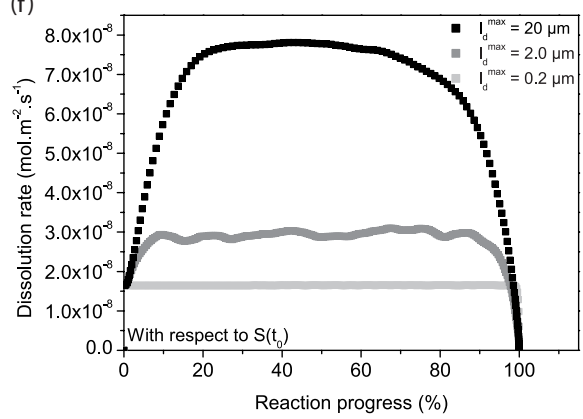

(i)

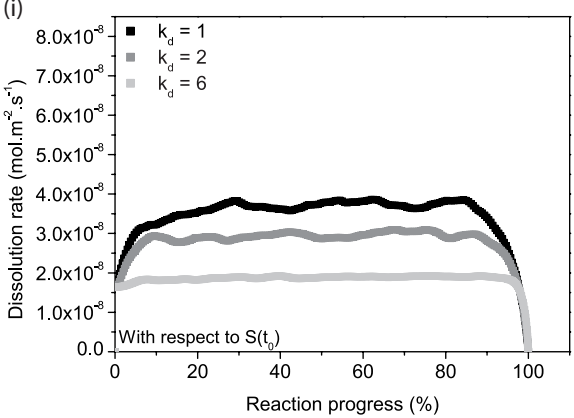




\section{algderect to $\mathrm{S}\left(\mathrm{t}_{0}\right)$}
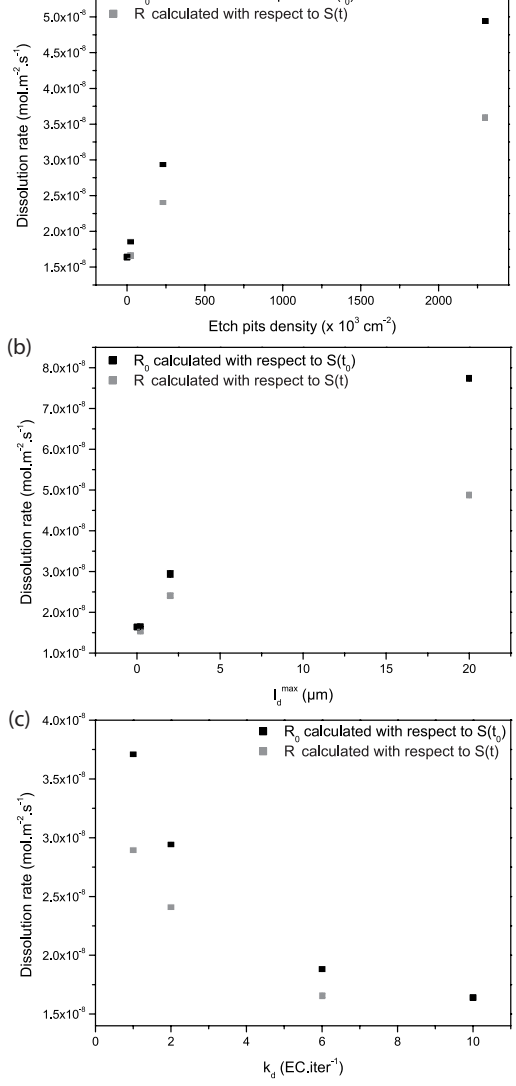
